\title{
Perkembangan Gamification dan Dampak Game Online terhadap Jiwa Manusia di Kota Pintar DKI Jakarta
}

\author{
Nur Kumala Dewi ${ }^{1}$, Arman Syah Putra ${ }^{2}$ \\ ${ }^{1}$ Program Studi Teknik Informatika, STMIK Muhamadiyah Jakarta, Jl. Kelapa Dua Wetan \\ ${ }^{2}$ Program Studi Sistem Informasi, STMIK Insan Pembangunan, Jl Raya Bitung Serang \\ e-mail:nkd.mandori@gmail.com ${ }^{1}$, armansp892@gmail.com ${ }^{2}$
}

Submitted Date: August $31^{\text {st }}, 2020$

Revised Date: September $27^{\text {th }}, 2020$
Reviewed Date: September $22^{\text {nd }}, 2020$

Accepted Date: September 30 ${ }^{\text {th }}, 2020$

\begin{abstract}
In this study, online games are a research problem that is raised, by raising all things in online games, the author wants to know the impact of online games that have been troubling society and the results of this study are suggestions that will make the basic ingredients of decision making in terms of online games has troubled all levels of society. This research method uses literature review and field review, with the two process methods used it will produce valid research, with research based on previous research, the research will be more renewable, and research carried out in the field will find out the problems in the field. There have been many studies discussing the effect of online games, and in this study discussing the impact on the human psyche. In this study, researchers took data from many parties who were deemed necessary, and made the basis of their research. This research will produce suggestions and proposals that will be applied in a smart city in making a policy in an online application that is troubling the public.
\end{abstract}

Keywords: Smart City; Online Game; Sick; Soul

\begin{abstract}
Abstrak
Dalam penelitian ini game online adalah masalah penelitian yang diangkat, dengan mengangkat semua hal dalam game online, penulis ingin mengetahui dampak dari game online yang sudah meresahkan masyarakat dan hasil dari penelitian ini adalah saran yang akan menjadikan bahan dasar dari pengambilan keputusan dalam hal game online yang sudah meresahkan semua lapisan masyarakat. Metode penelitian ini menggunakan tinjauan pustaka dan tinjauan lapangan, dengan kedua proses metode yang digunakan maka akan menghasilkan penelitian yang valid, dengan penelitian yang berdasarkan penelitian sebelumnya maka penelitian akan lebih terbarukan, dan penelitian yang dilakukan di lapangan akan mengetahui permasalahan dilapangan. Sudah banyak penelitian yang membahas tentang pengaruh game online, dan pada penalitian ini membahas dampak terhadap jiwa manusia, Pada penelitian ini peneliti mengambil data dari banyak pihak yang dianggap perlu, dan menjadikan dasar penelitiannya. Pada penelitian ini akan menghasilkan saran dan usulan yang akan diterapkan dalam sebuah kota pintar dalam mengambil sebuah kebijakan dalam sebuah aplikasi online yang sampai meresahkan masyarakat.
\end{abstract}

Kata Kunci : Kota Pintar; Game Online; Sakit; Jiwa

\section{Pendahuluan}

Organisasi Kesehatan Dunia atau World

Health Organizations (WHO)

menggolongkan gaming disorder atau kecanduan game sebagai penyakit gangguan mental dalam versi paling baru International Statistical Classification of Diseases (ICD) yaitu ICD-11. ICD-11 ini dipresentasikan dalam the World Health
Assembly pada Mei 2019 dan akan mulai berlaku pada tanggal 1 Januari 2022.

ICD adalah sebuah daftar klasifikasi medis yang isinya merupakan daftar penyakit, beserta gejala, tanda, dan penyebabnya. ICD ini adalah standar internasional yang digunakan seluruh praktisi kesehatan di dunia untuk melaporkan penyakit dan kondisi kesehatan manusia (Ulfa, 2017). 
$\begin{array}{ccc}\begin{array}{c}\text { ICD-11, } \\ \text { kecanduan }\end{array} & \text { WHO menjelaskan } \\ \text { bermain } & \begin{array}{c}\text { bahwa } \\ \text { game }\end{array}\end{array}$ merupakan disorders due to addictive behavior atau gangguan yang disebabkan oleh kebiasaan atau kecanduan. Gaming disorder sendiri merupakan pola perilaku bermain game baik game online maupun offline (Nurnainah, 2020), digital-gaming atau video gaming adalah tipe permainan yang biasa digunakan dalam permainan game online, dari hal ini maka banyak kegiatan terganggu termasuk kegiatan fisik di luar rumah seperti berolahraga dan aktivitas lainnya, hal ini mempunyai kosekuensi yang sangat berat, anak akan malas bergerak dan bisa menyebabkan banyak kerusakan di dalam tubuh (Setiawan, 2018).

Kecanduan game online juga dijelaskan dalam banyak jurnal ilmiah dan rumah sakit di bagian mental, banyak yang terganggu akibat terlalu banyak bermain game online, di Amerika tahun 2013 banyak digunakan oleh para professional kesehatan mental untuk mendiagnosis gangguan mental. DSM-5 mencatat gejala-gejala yang diusulkan oleh the American Psychiatric Association untuk internet gaming disorder antara lain meliputi:

1. Keasikan dengan game online.

2. Menunjukkan tanda-tanda kesedihan, kecemasan, dan lekas marah ketika jauh dari game online.

3. Ketidakmampuan untuk mengurangi permainan, upaya yang dilakukan untuk berhenti bermain game online gagal.

4. Menghiraukan kegiatan lain selain bermain game online.

5. Terus bermain meski menimbulkan masalah.

Dari kriteria yang diusulkan tersebut, diagnosis internet gaming disorder bisa dilakukan apabila seseorang mengalami lima atau lebih dari gejala-gejala di atas dalam setahun. Kondisi ini berlaku untuk kecanduan game online di internet atau di perangkat elektronik lainnya, meskipun kebanyakan lainnya orang mengalami kecanduan game online di internet (Suplig, 2017).

Masalah kecanduan game online sekarang sudah banyak dialami oleh banyak orang dari semua kalangan dan dari semua usia dan bisa mengalami kecanduan game online, dari masalah ini peneliti mengangkat penelitian tentang game online bisa mempengaruhi jiwa seseorang (C Motoh, Jurnadi, \& Fatmawati, 2020). Menggunakan metode dan cara apa saja dalam mengatasi hal kecanduan game online yang sudah terjadi di masyarakat dan sudah dalam sampai meresahkan (Ulfa, 2017).

Masalah yang diangkat dampak positif dan negatif dari game online bisa menyebabkan sakit dalam jiwa manusia dan menggunakan metode apa saja penelitian game online yang bisa menyebabkan sakit dalam jiwa manusia.

\section{Landasan Teori}

Pada jurnal ini menghasilkan data bahwa game online memiliki pengaruh yang sangat kuat dalam kehidupan prilaku pada mahasiswa, penelitian di jurnal ini menjelaskan bahwa jika mahasiwa makin sering bermain game online maka memiliki penurunan akademik, yang artinya nilai mengalami penurunan yang berimbas kepada index prestasi akademik (IPK) menurun, hal yang bisa memperbaikinya adalah dengan mengurangi bermain game online (Putra \& Fatrilia, 2020). Pada penelitian ini membuktikan warung internet yang menyediakan jasa game online mempunyai dampak buruk baik fisik dan mental pada anak yang kecanduan game online, penelitian ini dilakukan di wilayah sumedang, banyak hal buruk terjadi pada anak anak yang kecanduan game online, harus ada penjelasan kepada anak anak agar bisa mencegah kecanduan game online (Ismi \& Akmal, 2020). Pada jurnal ini menjelaskan bahwa game online bisa membuat waktu terbuang begitu saja, waktu memang terasa cepat pada saat bermain game online, hal yang bisa terjadi jika sudah terjangkit kecanduan game online adalah gangguan jiwa, takut, merasa tidak percaya diri, karena game online ingin tercapainya permainan yang dihayati dengan sepenuh hati jadi pemain bisa menjiwai dengan hati dan pikiran para pemain game online. Pada penelitian ini menghasilkan data yang bisa diketahui jika orang mengalami kecanduan game online, biasanya gejalanya adalah susah tidur (insomnia), sakit kepala, dan yang palin bahaya adalah terganggunya mental para pecandu game online (Ondang, J. Mokalu, \& Y. V. I. Goni, 2020), dan bisa disimpulkan bahwa kecanduan game online adalah sangat berbahaya bagi kesehatan. Kurang percaya dirinya para pecandu game online dikarenakan para pecandu hanya bisa percaya diri di arena maya bukan di dunia nyata, kontrol yang kurang baik antara dunia nyata dan dunia maya akan menimbulkan banyak masalah dengan prilaku anak. Segala sesuatu yang berlebihan adalah kurang bagus maka harus dibatasi dengan kontrol orang tua dan masyarakat. Tumbuh kembang anak bisa terganggu disebabkan oleh beberapa hal, anak harus bermain, sekolah, dan belajar dari ketiga 
kegiatan itu pasti yang paling disenangi adalah pada saat bermain, pemilihan permainan adalah sangat penting, harus imbang antara fisik dan mental pada permainan anak, game online jelas mempunyai pengaruh negatif jika dimainkan secara berlebihan dan tanpa pengawasan dari orang tua, anak bisa belajar hal baik dan hal buruk dari sebuah permainan game online, jika sudah kecanduan maka harus diobati dengan cara di terapi mentalnya agar anak lebih percaya diri di dunia nyata. Pada jurnal ini menjelasakan bahwa fenomena game online sekarang ini menjadi salah satu hal yang sangat diperhatikan para orang tua, orang tua ingin anaknya tidak mengalami kecanduan, ganggun mental adalah salah satu dari hal negatif dari kecanduan game online (Aprilianto, Fakhruddin, \& Syahindra, 2020), dengan menjaga anak dari kecanduan adalah hal yang bisa dilakukan orang tua dalam hal pencegahan. Sisi positif dari sebuah game online adalah bisa membuat anak kreatif dan meningkatkan daya imajinasi anak, bukan hanya hal negatif dari sebuah game online, permasalahannya adalah waktu bermain yang berlebihan, yang menyebabkan kecanduan, jika sudah kecanduan maka fisik dan mental akan banyak terganggu (Putra, et al., 2019).

\section{Metode Penelitian}

Pada penelitian ini menggunakan metode studi keperpustakaan dan studi lapangan, pada bab tiga ini menjelaskan metode dan car metode itu bekerja (Putra, et al., 2019), di bawah ini digambarkan framework penelitian agar lebih dimengerti semua pihak, ada pun gambar framework penelitian bisa dilihat di bawah ini:

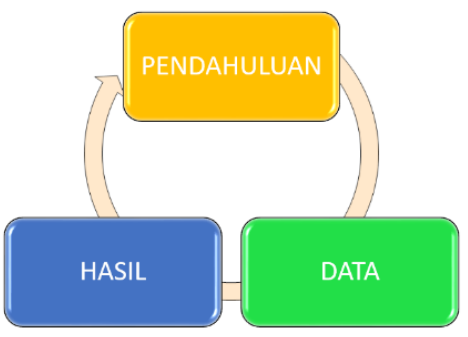

Gambar 1 Tahapan penelitian

Gambar 1 gambar metode yang digunakan dalam penelitian ini dengan menggunakan 3 tahapan, yaitu:

1) Penelitian Pendahuluan.

Pada awal penelitian menggunakan studi keperpusatakaan dan studi lapangan, dengan membaca maka akan membuat dasar penelitian sangat kuat karena bisa mengetahui masalah yang terjadi sekarang ini dan membuat peneltian kita menjadi terbaharukan, jurnal dan buku menjadi dasar penelitian ini, dan studi lapangan dengan melihat langsung orang orang yang mengalami kecanduan dalam game online (Dhamayanthie, 2020).

2) Data.

Hal yang dilakukan selanjutnya adalah dengan mengumpulkan data dari perpustakaan dan lapangan, adapun hal yang dilakukan dalam penelitian ini bisa dilihat di bawah ini:

A. Sumber data

Beberapa sumber di cari untuk mendapatkan data dalam penelitian ini, data yang didapat dalam penelitian ini adalah data primer dan data sekunder, penjelasannya bisa dilihat di bawah ini:

a. Data primer

Data yang didapat dari studi lapangan dengan melihat dan bertanya langsung di tempat yang akan diteliti, data ini menghasilkan data lapangan dan data wawancara. Data lapangan (observasi) didapat dari melakukan pengamatan secara langsung terhadap siswa pemain game. Data wawancara didapat dari hasil wawancara siswa pemain game dan psikolog.

b. Data sekunder

Pada data ini sumbernya tidak langsung atau dengan kata lain sumber data didapat dari hasil pengolahan data yang sudah dilakukan sebelumnya, data sekunder pada penelitian ini bersumber dari jurnal dan game. Jurnal yang berkaitan dengan masalah kesehatan dari pengaruh game. menuliskan bahwa sebanyak 71 responden atau 83,5\% dari seluruh responden yang memiliki kebiasaan bermain video game memiliki penurunan ketajaman penglihatan baik pada satu atau dua mata.

Game yang paling banyak dimainkan. Mayoritas jenis video game yang sering dimainkan adalah game online $(51,1 \%)$, playstation $(45,6 \%)$ dan sisanya penggemar game gadget $(3,3 \%)$.

B. Mengolah data

Setelah data didapat, data langsung diolah untuk keperluan peneitian, dan data diolah sesuai dengan metode yang di rancang dari awal. 
C. Analisis data

Setelah data diolah dan menghasilkan suatu hasil maka hasil yang dihasilkan di analisa demi menemukan informasi yang dicari dalam penelitian ini, penelitian ini menghasilakan informasi untuk kepentingan bersama. Analisa yang dilakukan mencakup:

a. Analisis banyak waktu yang digunakan Analisis banyak waktu yang digunakan dilakukan untuk mengukur dan mengelompokan siswa pemain game berdasarkan lama waktu yang dihabiskan.

b. Analisis perangkat yang digunakan Analisis perangkat yang digunakan untuk bermain game juga berpengaruh bagi dampak yang dihasilkan untuk pemain.

c. Analisis game yang dimainkan

Analisis game yang dimainkan dilakukan untuk mengetahui tingkat pengaruh dari game terhadap perilaku pemain.

d. Akhir penelitian

Akhir dari tahapan peneltian menghasil kan sesuatu informasi yang akan bisa menjadi landasan yang menjadikan pengambilan keputusan.

3) Hasil.

Pada bagian ini merupakan tahapan dari hasil dari sebuah penelitian dan bisa dibuktikan dalam usulan dari sebuah penelitian, usulan yang dihasilkan dalam penelitian ini akan diserahkan ke pihak yang terkait dalam upaya membantu menyelesaikan masalah yang ada.

\section{$4 \quad$ Hasil dan Pembahasan}

Banyak yang dapat diambil dalam sebuah permainan terutama game online (Setiawan, 2018), bisa hal negatif atau hal positif. Hal negatif yang diangkat dalam penelitian ini, banyak yang sudah terjadi dalam perkembangan game online seperti kecanduan dan sakit dalam hal kejiwaan seperti melupakan hal-hal penting seperti makan, data yang sudah terkumpul bisa dilihat pada Gambar 1 .

Tabel 1 Jenis Kelamin

\begin{tabular}{|l|c|c|c|}
\hline No & Kategori & Frekuensi & Persentase \\
\hline $\mathbf{1}$ & Pria & 85 & $85 \%$ \\
\hline $\mathbf{2}$ & Wanita & 15 & $15 \%$ \\
\hline
\end{tabular}

Sumber : Hasil survei penelitian 2020
Dari Table 1 di atas dapat diketahui jumlah partisipan terbanyak adalah pria, dengan persentase $85 \%$.

Tabel 2 Kenapa bermain game

\begin{tabular}{|c|l|c|c|}
\hline No & \multicolumn{1}{|c|}{ Alasan } & Nilai & Peresentasi \\
\hline $\mathbf{1}$ & Hobi & 45 & $45 \%$ \\
\hline $\mathbf{2}$ & Senang & 15 & $15 \%$ \\
\hline $\mathbf{3}$ & Iseng & 20 & $20 \%$ \\
\hline $\mathbf{4}$ & Bosan & 20 & $20 \%$ \\
\hline & Total & $\mathbf{1 0 0}$ & $\mathbf{1 0 0 \%}$ \\
\hline
\end{tabular}

Sumber : Hasil survei penelitian 2020

Dari table 2 di atas dapat diketahui jumlah partisipan terbanyak sebagai hobi, dengan persentase $45 \%$.

Tabel 3Lama bermain dalam seminggu

\begin{tabular}{|l|l|c|c|}
\hline No & \multicolumn{1}{|c|}{ Waktu } & Nilai & Persentase \\
\hline $\mathbf{1}$ & 3-10 Jam & 10 & $10 \%$ \\
\hline $\mathbf{2}$ & 12-20 Jam & 15 & $15 \%$ \\
\hline $\mathbf{3}$ & 22-30 Jam & 27 & $27 \%$ \\
\hline $\mathbf{4}$ & >33 Jam & 48 & $48 \%$ \\
\hline & Total & $\mathbf{1 0 0}$ & $\mathbf{1 0 0 \%}$ \\
\hline
\end{tabular}

Sumber : Hasil survei penelitian 2020

Waktu bermain $>33$ jam adalah mempunyai nilai tertinggi dalam seminggu yang artinya sudah mulai kecanduan game online.

Penelitian ini mengangkat masalah tentang dampak game online, dengan menganggkat masalah tersebut maka peneliti ingin mengetahui apakah dampak terburuk dari kecanduan game online, dengan masalah di atas maka penulis mengambil garis besar penelitian adalah di bawah ini:

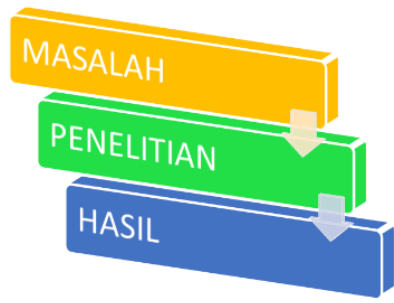

Gambar 2 Kerangka penelitian

Gambar 2 cara penulis dalam melakukan penelitian dalam mencari solusi untuk memecahkan masalah yang ada. Yang dilakukan pada penelitian ini dalam rangka menyelesaikan masalah adalah: 
a. Masalah

Candu adalah kata yang berhubungan dengan suatu ketergantungan dengan sesuatu, jika seseorang sudah mengalami kecanduan maka akan sangat bergantung sekali dengan hal yang dicandukan, jika seseorang sudah kecanduan maka banyak hal negatif yang akan didapat, terlebih lagi dari game online, dampak psikologis adalah dampak terburuk dari hal negatif karena mempengaruhi jiwa seseorang, game online dimainkan dari usia anak hingga orang tua dan banyak sudah kecanduan dengan game online, bahkan game online sudah masuk kedalam cabang olahraga yang di pertandingkan di event nasional dan internasional, dan Indonesia merupakan juara di event internasional, game online seperti mobile legend dan PUBG adalah permainan yang dimainkan di event internasional dan Indonesia adalah salah satu juara pada event tersebut, semua hal terdapat dua sisi yang bisa dijadikan hal positif, tetapi sisi negatif juga dilihat dalam game online tersebut, banyak yang menjadi candu dalam game online, pada penelitian ini penulis mengangkat masalah dampak kecanduan game online, dalam bab ini akan dibahas dampak dari kecanduan game online, dan dapat dilihat dalam bagian ke dua bab ke empat ini.

b. Penelitian

Dengan membaca dan melihat lapangan bisa menghasilkan data yang bisa dipergunakan dalam pengolahan data dalam penelitian ini, seperti keperpustakaan dan diambil dari jurnal yang terdahulu agar penulis tau sudah sejauh mana penelitian yang sudah dilakukan sebelumnya, dan penelitian yang ke dua dengan mengadakan survei langsung ke lapangan atau bertanya langsung ke pengguna game online yang sudah memainkannya lama dan dampaknya yang dirasakannya langsung, pada penelitian ini penulis juga memasukan hasil survei pada ketiga orang yang dianggap penting, dan hasil dari perpustakaan adalah dampaknya sudah makin parah dan sampai ada rumah sakit jiwa membuka ruangan khusus kecanduan game online, dengan hasil yang sudah didapat maka hasil dapat disimpulkan segera.

c. Hasil

Dampak positif dan negatif ada dalam sebuah kegiatan, apapun kegiatan itu dalam hal ini adalah game online yang sudah banyak memakan korban dengan kecanduan game online, ada kelebihan dan kekurangan dari sebuah game online, adapun bisa dilihat di bawah ini:

1. Kelebihan Game Online

Kelebihan dari game online adalah:
a. Menjauhkan dari stress.
b. Bisa menghabiskan waktu.
c. Bisa menjadi atlet E-Sport.
d. Melatih keseimbangan otak.

2. Kekurangan Game Online

Kekurangan dari game online adalah:
a. Kecanduan game online.
b. Lupa akan semua kegiatan.
c. Lalai akan tanggung jawab.
d. Sakit akan jiwanya.

Penelitian kali ini tidak hanya dari segi teori saja, penulis juga bertanya langsung kepada pengguna game online, dan dilakukan kepada beberapa orang langsung di lapangan pengguna game online, adapun hasil wawancara tersebut adalah:

1. Tommy, 18 tahun, mahasiswa mengatakan bahwa "Game online itu perlu karena fungsinya untuk menghilangkan stress kuliah".

2. Diaz, 25 tahun, Karyawan Swasta mengatakan bahwa "Game online ada dua sisi, dan lebih banyak negatifnya dibandingkan positifnya".

3. Tia, 19 tahun Mahasiswi mengatakan bahwa "Hanya di game online perempuan bisa di hargai setara dengan laki-laki".

Berdasarkan hasil wawancara di atas maka ada hal positif dan negatif dari permainan game online, dan lebih banyak negatifnya dari pada positifnya.

\section{Kesimpulan}

Hasil dari penelitian di atas bisa dilihat dari kesimpulan di bawah ini:

1. Hal negatif dari bermain game online adalah sebagai berikut:
a) Lupa Sholat
b) Hilangnya konsentrasi
c) Tidak hidup disiplin
d) Sakit jiwanya
e) Pemarah
f) Penyendiri
g) Lupa makan dan minum
h) Tidak hormat orang tua 
Dari hal buruk yang terjadi itu semua bisa dihindari dengan cara pencegahan dan sosialisasi akan hal negatif yang terjadi jika sudah mengalami kecanduan game online.

2. Hal positif dari bermain game online adalah sebagai berikut:

a) Anak lebih cerdas

b) Pemikirannya lebih maju

c) Mempererat silahturahmi

d) Kawannya lebih banyak di dunia maya

Harus banyak sosialisasi atau penyuluhan terhadap bahaya dari game online dan dampak baik buruknya terhadap kesehatan fisik dan psikis manusia, semua hal ada sisi negatif dan positifnya, maka harus diukur sejauh mana hal tersebut bisa berdampak negatif.

\section{Referensi}

Aprilianto, T., Fakhruddin, \& Syahindra, W. (2020). Dampak Game Online terhadap Pola Belajar Anak: Studi di Desa Ujung Tanjung III Kabupaten Lebong. J u r n a l H a w a, 64-80.

C Motoh, T., Jurnadi, F., \& Fatmawati, A. (2020). Dampak Game Online Terhadap Siswa Kelas XI IIS 1 Sma Negeri 3 Tolitoli. Nusantara: Jurnal Ilmu Pendidikan Vol. 1, NO. 1, JULI 2020, 1-5.

Dhamayanthie, I. (2020). Dampak Game Online Terhadap Perilaku Mahasiswa Akamigas Balongan. Jurnal Rekayasa, Teknologi, dan Sains Volume 4 Nomor 1, JANUARI 2020, 1315.

Ismi, N., \& Akmal. (2020). Dampak Game online terhadap Perilaku Siswa di Lingkungan SMA Negeri 1 Bayang. Journal of Civic Education (ISSN: 2622-237X) Volume 3 No. 1 2020, 1-10.

Nurnainah. (2020). Penyuluhan Tentang Dampak Bermain Game Online. Jurnal Peduli Masyarakat Volume 2 Nomor 2, Juni 2020 eISSN 2721-9747; p-ISSN 2715-6524, 87-90.

Ondang, G. L., J. Mokalu, B., \& Y. V. I. Goni, S. (2020). Dampak Game Online Terhadap Motivasi Belajar Mahasiswa Jurusan Sosiologi Fispol Unsrat. Jurnal Holistik ISSN: 1979-0481, 1-15.

Putra, A. S., \& Fatrilia, R. R. (2020). Paradigma Belajar Mengaji Secara Online Pada Masa Pandemic Coronavirus Disease 2019 (Covid-19). MATAAZIR: Jurnal Administrasi dan Manajemen Pendidikan, 49-61.

Putra, A. S., Warnars, H. L., Abbas, B. S., Trisetyarso, A., Suparta, W., \& Ho Kang, C. (2019). "Gamification in the e-Learning Process for children with Attention Deficit Hyperactivity Disorder (ADHD)". 1st 2018 Indonesian Association for Pattern Recognit INAPR, 182185.
Setiawan, H. S. (2018). “Analisis Dampak Pengaruh Game Mobile Terhadap Aktifitas Pergaulan Siswa Sdn Tanjung Barat 07 Jakarta”. P-Issn: 1979-276x, E-Issn: 2502-339x, Doi: 10.30998/Faktorexacta.V11i2.2338, 146-156.

Suplig, M. A. (2017). "Pengaruh Kecanduan Game Online Siswa Sma Kelas X Terhadap Kecerdasan Sosial Sekolah Kristen Swasta Di Makassar”. Jurnal Jaffray, Vol. 15, No. 2,, 77200.

Ulfa, M. (2017). "Pengaruh Kecanduan Game Online Terhadap Perilaku Remaja Di Mabes Game Center Jalan Hr.Subrantas Kecamatan Tampan Pekanbaru’.' Jom. Fisip Vol. 4 No. 1, 1-13. 